\title{
BMJ Open Association of sedentary behaviour patterns with dietary and lifestyle habits among public school teachers: a cross-sectional study
}

\author{
Leandro Dragueta Delfino (D) , ${ }^{1}$ William Rodrigues Tebar, ${ }^{1}$ Fernanda Caroline Gil, ${ }^{1}$ \\ Jefferson Marinho De Souza, ${ }^{1}$ Marcelo Romanzini, ${ }^{2}$ Romulo Araujo Fernandes, ${ }^{1}$ \\ Diego Giulliano Destro Christofaro ${ }^{1}$
}

To cite: Delfino LD, Tebar WR, Gil FC, et al. Association of sedentary behaviour patterns with dietary and lifestyle habits among public school teachers: a cross-sectional study. BMJ Open 2020;10:e034322. doi:10.1136/ bmjopen-2019-034322

- Prepublication history for this paper is available online. To view these files, please visit the journal online (http://dx.doi org/10.1136/bmjopen-2019034322).

Received 14 September 2019 Revised 06 January 2020 Accepted 08 January 2020
Check for updates

(C) Author(s) (or their employer(s)) 2020. Re-use permitted under CC BY-NC. No commercial re-use. See rights and permissions. Published by BMJ.

${ }^{1}$ Department of Physical Education, Universidade Estadual Paulista Julio de Mesquita Filho Faculdade de Ciencias e Tecnologia Campus de Presidente Prudente,

Presidente Prudente, São Paulo, Brazil

${ }^{2}$ Department of Physical

Education, Universidade

Estadual de Londrina, Londrina, Paraná, Brazil

Correspondence to Mr Leandro Dragueta Delfino; ledragueta@hotmail.com

\section{ABSTRACT}

Objectives To analyse the association of sedentary behaviour patterns with dietary and lifestyle habits among public school teachers.

Design Cross-sectional study.

Participants A sample of 245 teachers (186 women and 59 men) with mean age of $45.2( \pm 10.4)$ were randomly selected from public schools.

Primary and secondary outcome measure Sedentary behaviour was assessed by hours spent watching television, computer and cellphone/tablet use and in sitting position. Sedentary breaks were reported in a Likert scale in domains of work and leisure time. Dietary habits were assessed by weekly consumption of fruits, vegetables, dairy products, fried foods, sweets, grains, cereals, white meat, soft drinks and snacks. Physical activity, smoking, alcohol consumption and socioeconomic status were assessed by using questionnaires.

Results The prevalence of high sedentary behaviour, high sedentary breaks at work and at leisure was $57.9 \%, 67.7 \%$ and $70.2 \%$ in the sample, respectively. № relationship was observed of high sedentary behaviour with dietary and lifestyle habits in adjusted analysis. However, high sedentary breaks at work were associated with high consumption of dairy products $(\mathrm{OR}=1.93(\mathrm{Cl}$ 1.07 to 3.51)) and cereals ( $\mathrm{OR}=2.49$ ( $\mathrm{Cl} 1.05$ to 5.92)) and with being high physically active $(\mathrm{OR}=2.57(\mathrm{Cl} 1.14$ to 5.77)). High sedentary breaks at leisure time were associated with high consumption of fruits $(\mathrm{OR}=2.33(\mathrm{Cl}$ 1.28 to 4.23$))$ and vegetables $(\mathrm{OR}=1.91(\mathrm{Cl} 1.05$ to 3.49$))$ and with be high physically active $(\mathrm{OR}=2.34(\mathrm{Cl} 1.03$ to 5.35)). High sedentary breaks were associated with better dietary habits even among teachers with high sedentary behaviour.

Conclusion High sedentary breaks were associated with better dietary habits and with high levels of physical activity among public school teachers, even those with high sedentary behaviour.

\section{INTRODUCTION}

Sedentary behaviour is defined as the time spent in activities of energy expenditure of $\geq 1.5$ Metabolic equivalent of task - METs in seated, reclined or lying posture. ${ }^{1}$ Nowadays,
Strengths and limitations of this study

- Cross-sectional design does not allow cause and effect inference in this study.

- Subjective assessment of physical activity and sedentary behaviour (questionnaire) did not allow a more robust evidence.

- A randomly selected sample and analyses controlled by sex, age and socioeconomic status.

- Physical activity and breaks in sedentary behaviour were assessed in domains of occupation and leisure time.

- The association of sedentary breaks in different domains with dietary habits among teachers has not been previously analysed in literature.

people spend much of their awake time on this type of activities, resulting in an increased sedentary behaviour both at work and leisure time. $^{2}$

WHO report highlights that 3.2 million of deaths per year were attributed to sedentary lifestyle. ${ }^{3}$ Adult population spends around one-third to one-half of daily time in sedentary behaviour, with prolonged hours on screen devices as watching TV, using computers, participating in screen-based recreation or driving. ${ }^{4}$

The amount of time in sedentary behaviour has been widely evaluated in three ways: (i) checking for specific behaviours, such as television time; (ii) quantification of sedentary time in a specific domain (work, leisure or transportation); (iii) total time allocated to all manifestations of sedentary behaviour throughout the day. ${ }^{5}$ In this sense, a large proportion of daily sedentary behaviours has been accumulated at work environment, once studies observed office workers spend at least two-thirds of their working hours seated. ${ }^{67}$ 
Besides, due to technological advances, sitting position has become a normative stance. ${ }^{8}$

Sitting time has been related to unhealthy dietary habits in adults. ${ }^{1}$ Besides that, screen devices have been associated with exposure of food advertisements, which may lead to consumption of products of high energy density and low nutritional content. ${ }^{9}$ In this sense, the assessment of the relationship between sedentary patterns and dietary habits is important for public health, once adults with a healthy dietary pattern showed a more active lifestyle than those with unhealthy dietary patterns, ${ }^{10}$ and the association of physical activity and healthy dietary habits contributes to the prevention of diseases. ${ }^{11}$

However, how life habits of predominantly nonsedentary workers is affected by the levels of sedentary behaviour is not consensual in literature, mainly among teachers. In Brazil, there are more than 2.6 million teachers of basic and higher education, which represents a large professional category. ${ }^{12}$ Besides that, teachers' workload is characterised by a considerable physical requirement, once these professionals remain for $95 \%$ of their work activities in orthostatic position. ${ }^{13}$ In addition, teachers perform a high demand of repetitive activities, most of them in ergonomically inadequate environments and in a complex nature of the teaching professional's role. ${ }^{14}$ Teachers therefore have a non-sedentary physical activity profile, ${ }^{15}$ and teachers are categorised as moderately active in their work functions. ${ }^{16}$

Nevertheless, physically active jobs can be associated with increased sitting time during leisure, and the relationship between occupation type and sedentary behaviour outside work needs further research. ${ }^{17}$ Besides that, frequent breaks in sedentary activities have been considered as an important strategy to mitigate the health impairments of sedentary behaviour, once sedentary breaks with light activities (ie, walking down the corridor to talk to co-workers or extending the distance walking to the restroom) can lead to important health benefits. ${ }^{18}$

Thus, this study aimed to analyse in the same research the relation between sedentary behaviour and breaks in sedentary time at work and leisure with dietary and lifestyle habits in public school teachers, controlled by confounding factors such as sex, age and socioeconomic status (SES).

\section{METHODS}

An observational study with cross-sectional design was performed according to the Ethics and Research Committee of University. All participants were duly informed about the objectives and procedures of the research and those who agreed to participate signed the informed consent term.

\section{Sample selection and inclusion criteria}

Sample was selected in the city of Presidente Prudente, which is located in the southern region of Brazil. There are about 207625 inhabitants in the city of Presidente
Prudente, which has a human development index of 0.846 (Brazilian Institute of Geography and Statistics, 2017).$^{19}$ According to the City Department of Education, the number of public school teachers in the city is approximately 650 , allocated in 23 schools.

Data collection was performed during the period of collective pedagogical work, at which time all teachers of the institution were present, so that it did not interfere in their pedagogical activities. The teachers were invited to participate for at least three times by the school manager. To participate in the research, the following inclusion criteria were adopted: (i) be an effective teacher (approved in civil service exam) or hired by the state education network; (ii) participate in all procedures (questionnaire, anthropometry) and sign the informed consent term.

\section{Sample calculation}

The minimum sample size was calculated for a greater research project about health behaviours in teachers, which considered a prevalence outcome of $50 \%$, adopted in epidemiological studies with unknown prevalence or several outcomes, ${ }^{20}$ a population of 650 public school teachers in the city, a CI of $95 \%$, a test power of $80 \%$ and a tolerable error of $5 \%$, which provided a simple random sample of 242 teachers. From all 23 schools in the city invited to participate, only 13 gave permission to collect the data; all the 13 schools were visited and all the teachers of these schools were invited to participate.

\section{Organisation of data collection}

Data collection was performed between the second semester of 2016 and first semester of 2017. The application of questionnaires was carried in the school environment by previously trained researchers, so that any doubts were promptly resolved. Evaluations of the anthropometric measurements (weight, height and waist circumference) were performed in a specific room provided by the school manager. In order to avoid possible constraints, male teachers were evaluated by a male researcher and female teachers by a female researcher.

\section{Sedentary behaviour}

The assessment of this variable was based on the Sedentary Behaviour Questionnaire, ${ }^{21}$ through the self-reported hours in a typical weekday and at weekend that teachers spent in television viewing, using the computer, using cell phone/tablet as well as in sitting time in a typical weekday. The responses were categorised into: (i) less than 1 hour (0 hour computed); (ii) more than 1 hour but less than 2 hours (1 hour computed); (iii) more than 2 hours but less than 3 hours (2 hours computed); (iv) more than 3 hours but less than 4 hours (3 hours computed); (v) more than 4 hours but less than 5 hours (4hours computed); (vi) more than 5 hours ( 5 hours computed).

The mean of hours was calculated from a typical weekday and from a weekend day reported for each behaviour (television, computer, cellphone/tablet) and 
the sedentary behaviour was calculated by the sum of the mean hours and total daily hours reported in sitting. The sample was classified as 'high sedentary behavior' and 'low sedentary behavior' according to cut-off point of 8 and more hours. ${ }^{22}$

Breaks in sedentary behaviour at work and in leisure time were self-reported according to the following questions:

- In your work environment, how frequent do you get up to go to the bathroom, drink water or perform other activities that require standing or walking for at least a short time?

- In your leisure time, how frequent do you get up to go to the bathroom, drink water or perform other activities that require standing or walking for at least a short time?

The answers were presented on a Likert scale: (i) never; (ii) rarely; (iii) sometimes; (iv) often; and (v) always. The sample was divided into 'high sedentary breaks' (often, always) and 'low sedentary breaks' (never, rarely, sometimes) for each domain.

\section{Anthropometry}

Measurements of body mass, height and waist circumference were collected with participants being barefoot and wearing light clothing. Body mass was measured using a digital scale (Plenna brand) with an accuracy of $0.1 \mathrm{~kg}$. Stature was evaluated by a portable stadiometer (Sanny brand, American Medical of Brazil) with a maximum extension of $2.20 \mathrm{~m}$ and precision of $0.1 \mathrm{~cm}$. Waist circumference was collected through the middle point between the last rib and superior border of iliac crest ${ }^{23}$ by an inextensible measuring tape with precision in millimetres and extension of $2 \mathrm{~m}$.

\section{Dietary habits, consumption of alcohol and smoking}

Dietary habits were assessed by a food frequency questionnaire about the weekly frequency (days/week) consumption of fruits, vegetables, dairy products (ie, milk, yoghurt, cheese, creamy cheese), fried foods, sweets, grains (ie, bean, rice, pea, lentil, chickpea, soy), white meat or fish, soft drinks, snacks and cereals (ie, oat, granola, cornflakes). This instrument was based on questionnaire proposed by the Brazilian Surveillance System for Risk and Protective Factors for Chronic Diseases by Telephone Survey, ${ }^{24}$ which assess the frequency of consumption through the number of days per week and defines as regular consumption the frequency of $\geq 5$ days per week for different types of food. In this sense, the food consumption was classified as high consumption ( $\geq 5$ days/week) and 'low consumption' (4 or less days/ week).

The consumption of alcohol and smoking was assessed through questions of the Brazilian Center of Information on Psychotropic Drugs. ${ }^{25}$ The alcohol consumption questionnaire consisted of the frequency of alcoholic beverages consumed in the last 30 days and the number of doses per day. Teachers who report alcohol consumption for at least 1-2 days/week and 1-2 doses per day were classified as 'high alcohol consumption'. The smoking habit was assessed by questions about the number of days smoked in the last 30 days, as well as the number of cigarettes per day. Teachers who reported smoking any cigarettes in the previous 30 days were considered as smokers. This type of instrument was previously used in epidemiological study. ${ }^{26}$

\section{Practice of physical activity}

The practice of physical activity was evaluated by using Baecke Questionnaire. ${ }^{27}$ This instrument evaluates the habitual practice of physical activities through three different domains (physical activity at work, physical activity in leisure and sports practice and physical activity outside work), presenting a dimensionless score that ranges from 1 to 5 points for each domain, providing a total score from 3 to 15 points through the sum of the three assessed domains. The cut-off point for classifying the individuals was defined by quartiles: 'high active' included those individuals who were in the highest quartile for the Baecke score (fourth quartile), 'moderately active' those located in intermediate quartiles (third and second quartiles) and 'less active' those subjects located in the first quartile.

\section{Socioeconomic status}

Brazilian Economic Classification Criteria ${ }^{28}$ was used to assess the SES. This questionnaire takes into account the degree of education, and the presence and quantity of certain rooms and goods in the home (television, DVD, radio, bathroom, car, washing machine, freezer). The instrument classifies the sample by scores into classes from the highest to lowest: A1, A2, B1, B2, C1, C2, D and E. The sample was further classified as high SES (A1, A2), medium SES (B1, B2, C1) and low SES (C2, D, E).

\section{Statistical analysis}

Data distribution was assessed by Kolmogorov-Smirnov test and, due to non-normal distribution, the characteristics of sample were expressed as median and IQR. The median differences were verified by the Wilcoxon rank test for dependent samples and by Mann-Whitney $U$ test for independent samples. The correlation between breaks in sedentary behaviour with sedentary time in different domains was analysed by Spearman correlation coefficient. The association of high sedentary behaviour and breaks in sedentary time with independent variables (dietary habits, smoking, alcohol consumption and physical activity) were evaluated by the $\chi^{2}$ test. Variables with associations of $p \leq 0.200$ were considered in the multiple model, performed by binary logistic regression adjusted by sex, age and socioeconomic condition. For a clustering analysis of sedentary behaviour and breaks, the sample was divided into three groups: high sedentary behaviour with low sedentary breaks (group 1), high sedentary behaviour with high sedentary breaks (group 2) and low sedentary behaviour (group 3). Statistical significance 
Table 1 Characterisation of the sample according to sedentary behaviour level in public school teachers

\begin{tabular}{|c|c|c|c|}
\hline & Low SB & High SB & \\
\hline Variable & Median (IR) & Median (IR) & P value* \\
\hline Age (years) & $49.0(12.0)$ & $45.0(17.0)$ & 0.017 \\
\hline Body mass index $\left(\mathrm{kg} / \mathrm{m}^{2}\right)$ & $26.5(7.4)$ & $27.2(7.8)$ & 0.445 \\
\hline Waist circumference (centimetres) & $85.0(20.0)$ & $88.0(21.0)$ & 0.334 \\
\hline Fruits (days/week) & $5.0(4.0)$ & $5.0(4.0)$ & 0.330 \\
\hline Vegetables (days/week) & $6.0(3.0)$ & $6.0(4.0)$ & 0.307 \\
\hline Dairy products(days/week) & $7.0(4.0)$ & $5.0(5.0)$ & 0.164 \\
\hline Fried foods (days/week) & $1.0(1.0)$ & $1.0(1.0)$ & 0.216 \\
\hline Sweets (days/week) & $3.0(4.0)$ & $3.0(4.0)$ & 0.794 \\
\hline Grains (days/week) & $7.0(1.0)$ & $7.0(2.0)$ & 0.160 \\
\hline Cereals (days/week) & $2.0(4.0)$ & $2.0(3.0)$ & 0.500 \\
\hline White meat (days/week) & $4.0(3.0)$ & $3.0(3.0)$ & 0.354 \\
\hline Soft drinks (days/week) & $1.0(2.0)$ & $1.0(2.0)$ & 0.122 \\
\hline Snacks (days/week) & $0.0(0.0)$ & $0.0(1.0)$ & 0.003 \\
\hline Alcoholic beverages (doses/day) & $0.0(1.0)$ & $0.0(3.0)$ & 0.001 \\
\hline Smoking (cigarettes/day) & $0.0(0.0)$ & $0.0(0.0)$ & 0.595 \\
\hline Physical activity (Baecke score) & $7.3(2.4)$ & $7.4(2.2)$ & 0.369 \\
\hline Breaks in SB at work (frequency) & $4.0(2.0)$ & $4.0(2.0)$ & 0.741 \\
\hline Breaks in SB at leisure time (frequency) & $4.0(2.0)$ & $4.0(1.0)$ & 0.907 \\
\hline
\end{tabular}

${ }^{*} \mathrm{P}$ value for Mann-Whitney $U$ test.

$\mathrm{IR}$, Interquartile range; SB, sedentary behaviour.

was fixed at $5 \%$ and the $95 \%$ CI was adopted, with analyses in the software SPSS V.15.0.

\section{Patient and public involvement}

Patients and the public were not involved in the design or planning of the study.

\section{RESULTS}

The sample consisted of 245 individuals ( 38\% of the public school teachers from the city), with 186 females $(76 \%), 59$ males $(24 \%)$ and a mean age of $45.2( \pm 10.4)$ years. The prevalence of high SES was $5.7 \%$ in the sample, followed by $91.0 \%$ of medium SES, and $3.3 \%$ of low SES. A prevalence of $57.9 \%$ of the sample was classified as high sedentary behaviour. Median values of sedentary behaviour in a typical weekday and at weekend were the same in the sample (6.0 hours $(\mathrm{IQR}=6.0)$, $\mathrm{p}$ value for Wilcoxon rank's test $=0.360$ ); however, higher values of television viewing and lower values of computer use at weekend than weekday were observed ( $p$ value for Wilcoxon rank test $=0.001$ for both). Table 1 presents information regarding sample characterisation according to low and high sedentary behaviour. Teachers with high sedentary behaviour presented lower age $(p=0.017)$ and higher consumption of snacks $(\mathrm{p}=0.003)$ and alcoholic beverages $(0.001)$ than teachers with low sedentary behaviour.
Table 2 presents relation between prevalence of high sedentary behaviour and high consumption of foods and lifestyle habits. It was observed a higher prevalence of high sedentary behaviour among teachers with high consumption of alcoholic beverages than those with low alcoholic beverages consumption $(67.0 \%$ vs $50.0 \%)$.

Table 3 presents the magnitude of associations between high sedentary behaviour and variables with a $p$ value $\leq 0.200$ in $\chi^{2}$ analysis. No significant relationship was observed after adjustment for confounding factors (sex, age and SES).

Table 4 shows the associations of breaks in sedentary behaviour at work and at leisure time with dietary and lifestyle habits. High breaks in sedentary behaviour were reported by $67.7 \%$ of sample in the work domain and $70.2 \%$ at leisure time. It was observed that teachers with high breaks in sedentary behaviour at work were almost twice as likely to have high consumption of dairy products, 2.5 times more likely to have high consumption of cereals and 2.6 times more likely to be moderately and high active. When considering breaks in sedentary behaviour at leisure time, teachers who reported high sedentary breaks were more likely to have high consumption of fruits and vegetables, and more likely to be high actives. The correlation coefficient between breaks at work and breaks at leisure time was 0.408 ( $p$ value for Spearman=0.001). According to sedentary time, the amount of breaks at 
Table 2 Relation of high sedentary behaviour with dietary and lifestyle habits in public school teachers

\begin{tabular}{|c|c|c|c|c|}
\hline & Total $(n=245) n$ & $\begin{array}{l}\text { High sedentary behaviour } \\
(n=142) n(\%)\end{array}$ & $\chi^{2}$ value & $P$ value \\
\hline \multicolumn{5}{|l|}{ Fruit } \\
\hline Low consumption & 108 & $68(63.0)$ & 2.278 & 0.131 \\
\hline High consumption & 135 & $72(53.3)$ & & \\
\hline \multicolumn{5}{|l|}{ Vegetable } \\
\hline Low consumption & 77 & $46(59.7)$ & 0.245 & 0.621 \\
\hline High consumption & 165 & $93(56.4)$ & & \\
\hline \multicolumn{5}{|l|}{ Dairy product } \\
\hline Low consumption & 93 & $58(62.4)$ & 1.262 & 0.261 \\
\hline High consumption & 149 & $82(55.0)$ & & \\
\hline \multicolumn{5}{|l|}{ Fried Food } \\
\hline Low consumption & 221 & $124(56.1)$ & 2.212 & 0.137 \\
\hline High consumption & 19 & $14(73.7)$ & & \\
\hline \multicolumn{5}{|l|}{ Sweet } \\
\hline Low consumption & 167 & $92(55.1)$ & 1.392 & 0.238 \\
\hline High consumption & 76 & $48(63.2)$ & & \\
\hline \multicolumn{5}{|l|}{ Grains } \\
\hline Low consumption & 41 & 27 (65.9) & 1.353 & 0.245 \\
\hline High consumption & 200 & $112(56.0)$ & & \\
\hline \multicolumn{5}{|l|}{ Cereal } \\
\hline Low consumption & 198 & $116(58.6)$ & 0.795 & 0.372 \\
\hline High consumption & 43 & $22(51.2)$ & & \\
\hline \multicolumn{5}{|l|}{ White meat } \\
\hline Low consumption & 167 & $101(60.5)$ & 2.301 & 0.129 \\
\hline High consumption & 74 & $37(50.0)$ & & \\
\hline \multicolumn{5}{|l|}{ Soft drink } \\
\hline Low consumption & 225 & $130(57.8)$ & 0.014 & 0.905 \\
\hline High consumption & 16 & $9(56.3)$ & & \\
\hline \multicolumn{5}{|l|}{ Snack } \\
\hline Low consumption & 235 & $135(57.4)$ & 0.103 & 0.748 \\
\hline High consumption & 3 & $2(66.7)$ & & \\
\hline \multicolumn{5}{|l|}{ Alcoholic beverage } \\
\hline Low consumption & 136 & $68(50.0)$ & 7.135 & 0.008 \\
\hline High consumption & 109 & $73(67.0)$ & & \\
\hline \multicolumn{5}{|l|}{ Smoking } \\
\hline Non-smoker & 229 & $131(57.2)$ & 0.365 & 0.546 \\
\hline Smoker & 17 & $11(64.7)$ & & \\
\hline \multicolumn{5}{|l|}{ Physical activity } \\
\hline Less active & 53 & 35 (58.3) & & \\
\hline Moderately active & 128 & $40(63.5)$ & 1.401 & 0.496 \\
\hline High active & 65 & $67(54.5)$ & & \\
\hline
\end{tabular}

work was correlated to computer use $(\mathrm{r}=0.126, \mathrm{p}=0.049)$, cell phone/tablet $(\mathrm{r}=0.171, \mathrm{p}=0.007)$ and sitting time $(\mathrm{r}=-0.185, \mathrm{p}=0.007)$. No correlation between breaks at home and domains of sedentary behaviour was observed in Spearman correlation coefficient test.

Table 5 presents a clustering association analysis of different patterns of sedentary behaviour with dietary and 
Table 3 Multivariable-adjusted ORs and 95\% Cls for association between high sedentary behaviour and independent variables in teachers

\begin{tabular}{|c|c|c|c|}
\hline & OR & $95 \% \mathrm{Cl}$ & $P$ value \\
\hline \multicolumn{4}{|l|}{ Fruit } \\
\hline Low consumption & 1.00 & Reference & - \\
\hline High consumption & 0.84 & 0.48 to 1.46 & 0.534 \\
\hline \multicolumn{4}{|l|}{ Fried food } \\
\hline Low consumption & 1.00 & Reference & - \\
\hline High consumption & 1.54 & 0.51 to 4.63 & 0.445 \\
\hline \multicolumn{4}{|l|}{ White meat } \\
\hline Low consumption & 1.00 & Reference & - \\
\hline High consumption & 0.67 & 0.38 to 1.20 & 0.179 \\
\hline \multicolumn{4}{|l|}{ Alcoholic beverage } \\
\hline Low consumption & 1.00 & Reference & - \\
\hline High consumption & 1.63 & 0.95 to 2.81 & 0.076 \\
\hline
\end{tabular}

Adjusted for sex, age and socioeconomic status.

lifestyle habits of public school teachers. Teachers with high sedentary behaviour, but with high sedentary breaks at work and leisure (group 2) were 3.38 times more likely to have high consumption of fruits than those teachers with high sedentary behaviour and low sedentary breaks (group 1). The odds to have high consumption of fruits were also higher among teachers with low sedentary behaviour (group 3) when compared with the first group. Teachers located into group 2 were 3.6 times more likely to have high consumption of dairy products and 2.3 times more likely to be highly active when compared with group 1 . These results were observed independently of sex, age and SES.

\section{DISCUSSION}

This study observed a prevalence of $58 \%$ of high sedentary behaviour in public school teachers. However, teachers with high breaks in sedentary behaviour were associated with better dietary habits and physical activity, even among those with high sedentary behaviour, independently of sex, age and SES.

The sample of this study consisted a majority of females $(76 \%)$, which appears to be a trend in the area of basic education. This could be a reflection of the insertion of women in the work environment, from the second half of the twentieth century, especially in functions of teaching and nursing, considered as care functions and an extension of domestic activities. ${ }^{13}$ It should be highlighted that, according to UNESCO,${ }^{29}$ the prevalence of Brazilian female teachers is $81.3 \%$, being even higher than in this study.

The majority of females in the study sample revealed a possible common scenario for other studies involving teachers: the presence of double tasks (school and domestic). This factor may be responsible for the decrease in women's health, leading to insufficient time for leisure, rest and hours of sleep, which would imply high levels of stress, less time to perform physical activities and a greater probability of alcohol consumption. ${ }^{12}$ The prevalence of alcohol consumption was high in the sample $(44.4 \%)$. Therefore, the peculiarities of teaching career, coupled with the double tasks of women, may suggest reasons for the high consumption of alcoholic beverages, being further aggravated by the report of association of sedentary behaviour with alcohol consumption and unhealthy dietary pattern in earlier study. ${ }^{30}$ These findings meet the results of this study, once teachers with high alcohol consumption showed higher prevalence of high sedentary behaviour than teachers with low alcohol consumption $(67.0 \%$ vs $50.0 \%)$. It was also observed that alcohol consumption associated with television viewing time were factors that encourage excessive eating, ${ }^{31}$ which may impair even more the dietary habits of teachers with high sedentary behaviour and high alcohol consumption over time.

In this study, teachers with high breaks in sedentary behaviour at work were more likely to have high consumption of dairy products and cereals, and more likely to be physically actives. Regarding breaks in sedentary behaviour at leisure time, teachers who report high breaks in this domain were more likely to have high consumption of fruits and vegetables, and more likely to be physically active. Convergently with healthy eating habits as observed, the frequent sedentary breaks at work and leisure have been associated with lower metabolic risk, in regard to adiposity triglyceride levels. ${ }^{32}$ Another important factor is that breaks in sedentary behaviour may be performed even by light intensity activities and it is known that light intensity physical activity increases the metabolic rate and the energy cost of daily activities, which can significantly contribute to increase energy expenditure. ${ }^{33}$ By this way, teachers with higher physical activity practice, even in light intensity, may present greater physical fitness to withstand physiological workloads than those who were predominantly sedentary, and may perceive the standing time along the teaching activities as less intensely. ${ }^{14}$

This study compared the dietary habits according to groups with different sedentary behaviour patterns. The high breaks in sedentary behaviour contribute to an increase in the chance of high consumption of fruits and cereals even among teachers with high sedentary behaviour. A possible hypothesis is that breaks in sedentary time may provide opportunities to have more access to healthy food choices, which are not always available in the sedentary setting, whether at work or at leisure. Another hypothesis is that the fragmentation of sedentary behaviour may mitigate the influence of sedentary behaviour on unhealthy dietary habits.

High breaks in sedentary behaviour were also associated with higher chance of being highly active among teachers with high sedentary behaviour, which was not observed in teachers with low sedentary behaviour. This observation 
Table 4 Multivariable-adjusted ORs and 95\% Cls for association between high breaks in sedentary behaviour with dietary and lifestyle habits in public school teachers

\begin{tabular}{|c|c|c|c|c|c|c|}
\hline & \multicolumn{3}{|c|}{ High breaks in SB at work $(n=166)$} & \multicolumn{3}{|c|}{ High breaks in SB at leisure time $(n=172)$} \\
\hline & OR & $95 \% \mathrm{Cl}$ & $P$ value & OR & $95 \% \mathrm{Cl}$ & $P$ value \\
\hline \multicolumn{7}{|l|}{ Fruit } \\
\hline Low consumption & 1.00 & Reference & - & 1.00 & Reference & - \\
\hline High consumption & 1.62 & 0.90 to 2.92 & 0.108 & 2.33 & 1.28 to 4.23 & 0.005 \\
\hline \multicolumn{7}{|l|}{ Vegetable } \\
\hline Low consumption & 1.00 & Reference & - & 1.00 & Reference & - \\
\hline High consumption & 1.63 & 0.89 to 3.01 & 0.116 & 1.91 & 1.05 to 3.49 & 0.035 \\
\hline \multicolumn{7}{|l|}{ Dairy product } \\
\hline Low consumption & 1.00 & Reference & - & 1.00 & Reference & - \\
\hline High consumption & 1.93 & 1.07 to 3.51 & 0.029 & 1.36 & 0.76 to 2.44 & 0.298 \\
\hline \multicolumn{7}{|l|}{ Fried food } \\
\hline Low consumption & 1.00 & Reference & - & 1.00 & Reference & - \\
\hline High consumption & 0.89 & 0.29 to 2.73 & 0.838 & 0.94 & 0.32 to 2.73 & 0.947 \\
\hline \multicolumn{7}{|l|}{ Sweet } \\
\hline Low consumption & 1.00 & Reference & - & 1.00 & Reference & - \\
\hline High consumption & 1.10 & 0.60 to 2.05 & 0.743 & 1.21 & 0.65 to 2.24 & 0.541 \\
\hline \multicolumn{7}{|l|}{ Grains } \\
\hline Low consumption & 1.00 & Reference & - & 1.00 & Reference & - \\
\hline High consumption & 1.77 & 0.87 to 3.58 & 0.115 & 1.11 & 0.53 to 2.33 & 0.773 \\
\hline \multicolumn{7}{|l|}{ Soft drink } \\
\hline Low consumption & 1.00 & Reference & - & 1.00 & Reference & - \\
\hline High consumption & 0.67 & 0.21 to 2.19 & 0.518 & 0.48 & 0.16 to 1.44 & 0.193 \\
\hline \multicolumn{7}{|l|}{ Cereal } \\
\hline Low consumption & 1.00 & Reference & - & 1.00 & Reference & - \\
\hline High consumption & 2.49 & 1.05 to 5.92 & 0.038 & 2.04 & 0.87 to 4.80 & 0.100 \\
\hline \multicolumn{7}{|l|}{ White meat } \\
\hline Low consumption & 1.00 & Reference & - & 1.00 & Reference & - \\
\hline High consumption & 0.61 & 0.33 to 1.13 & 0.120 & 1.14 & 0.61 to 2.12 & 0.678 \\
\hline \multicolumn{7}{|l|}{ Alcoholic beverage } \\
\hline Low consumption & 1.00 & Reference & - & 1.00 & Reference & - \\
\hline High consumption & 0.97 & 0.55 to 1.72 & 0.929 & 0.95 & 0.53 to 1.68 & 0.951 \\
\hline \multicolumn{7}{|l|}{ Smoking } \\
\hline Low consumption & 1.00 & Reference & - & 1.00 & Reference & - \\
\hline High consumption & 1.00 & 0.32 to 3.08 & 0.995 & 0.84 & 0.30 to 2.41 & 0.751 \\
\hline \multicolumn{7}{|l|}{ Physical activity } \\
\hline Less active & 1.00 & Reference & - & 1.00 & Reference & - \\
\hline Moderately active & 2.60 & 1.28 to 5.28 & 0.008 & 1.75 & 0.87 to 3.55 & 0.116 \\
\hline High active & 2.57 & 1.14 to 5.77 & 0.022 & 2.34 & 1.03 to 5.35 & 0.043 \\
\hline
\end{tabular}

Adjusted for sex, age, and socioeconomic level.

$\mathrm{SB}$, sedentary behaviour.

reinforces the concept that sedentary behaviour and sufficient levels of physical activity were not an inverse of each other. ${ }^{34}$ Besides that, breaks in sedentary behaviour may lead to better healthy habits as healthy foods consumption and physical activity engaging even among those with high sedentary behaviour.

This study is limited by its cross-sectional design, which prevents the analysis of cause and effect. The self-report 
Table 5 Multivariable-adjusted ORs and 95\% Cls for clustering association of different sedentary behaviour patterns with independent variables in public school teachers

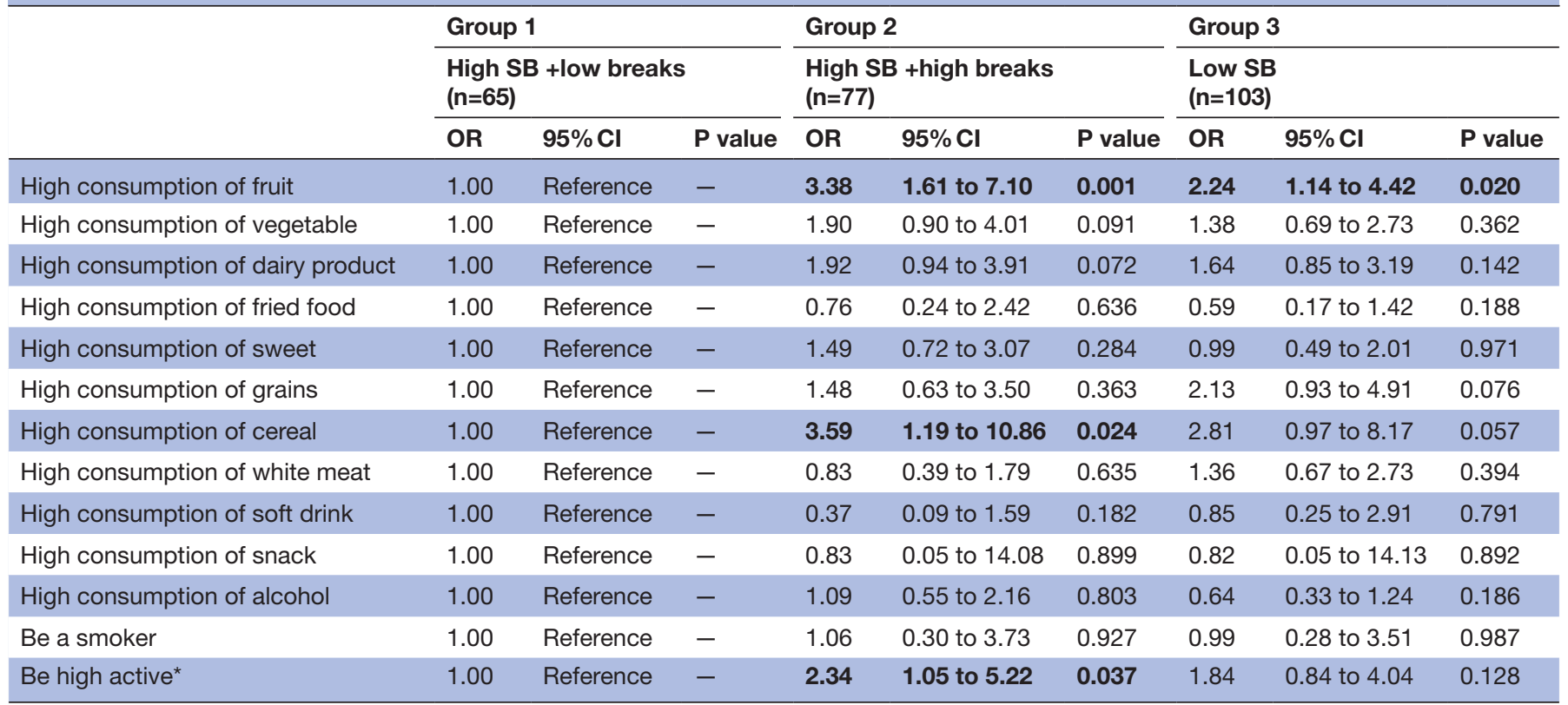

Analysis adjusted by sex, age and socioeconomic status. High SB=SB of 8 and more hours/day; low SB below 8 hours/day; low breaks=reported to break SB never, rarely or sometimes for both work and leisure time domains; high breaks=reported to break SB often or always for both work and leisure time domains.

${ }^{*}$ Fourth quartile of Baecke score. Bold values are statistically significant.

$\mathrm{SB}$, sedentary behaviour.

assessment of variables is another factor to be considered and may be vulnerable to biases. Sitting time was assessed in overall and its measurement in different domains will provide major inferences. Besides, due to this study having assess only to teachers, the inference about lifestyle behaviours of other workers is another important limitation, which does not allow to compare different groups of workers in regard to the same variables and consequently to extrapolate the findings to other populations. Another important limitation was the lack of assessment about how many servings per day was consumed for each food, being assessed only the frequency in days per week. Otherwise, advancements in this study were the assessment of the different sedentary patterns in a specific and important category of workers, who perform light intensity physical activities during almost all their work time, where most studies concentrate their efforts and investigation on how sedentary behaviour and lifestyle habits are associated. It should also be noted that data collection was performed face-to-face survey, and anthropometry was objectively measured in the workplace, which allows higher veracity of information.

In conclusion, this study observed no independent association of sedentary behaviour with dietary habits and lifestyle factors among teachers; however, high breaks in sedentary behaviour were associated with healthier dietary habits (ie, high consumption of fruits, vegetables, dairy products and cereals) and with high levels of physical activity. These positive results were observed even among teachers with high levels of sedentary behaviour, when compared with those with high sedentary behaviour and low breaks in sedentary behaviour. Further investigation are needed to extrapolate these results to other types of workers and to analyse these associations over the time. However, evidence-based information about teachers is helpful to lead positive behavioural health changes of this large sample of workers, as well as to all the people who are dependent on their professional acting.

Acknowledgements The authors would like to thank the education department of Presidente Prudente for the authorisation to conduct the research procedures in the schools, the Managers of the schools who allowed that teachers were evaluated and for the teachers who agreed to participate in the research.

Contributors We declare that all authors participated in this study based on the following criteria about authorship recommendations: substantial contributions to the conception or design of the work (LDD, WRT, DDC, MR, RAF); data collection (LDD, JMDS, FCG, WRT); data analysis and/or interpretation of data for the work (LDD, WRT, DDC); drafting the work or revising it critically for important intellectual content (LDD, WRT, DDC, MR, RAF); final approval of the version to be published (all the authors); and agreement to be accountable for all aspects of the work in ensuring that questions related to the accuracy or integrity of any part of the work are appropriately investigated and resolved (all the authors).

Funding This study is funded in part by the Coordenação de Aperfeiçoamento de Pessoal de Nível Superior (Finance Code 001). We are grateful to PROPG/PROPEEdital 12/2019 for the assistance to pay the publication fee.

\section{Competing interests None declared.}

Patient consent for publication Not required.

Ethics approval All procedures performed in studies involving human participants were in accordance with the ethical standards of the institutional and/or national research committee and with the 1964 Helsinki Declaration and its later amendments or comparable ethical standards. Informed consent was obtained from all individual participants included in this study. The Research Ethics Committee 
involving Human Beings of UNESP in the São Paulo State University approved this study (Protocol: 72191717.9.0000.5402).

Provenance and peer review Not commissioned; externally peer reviewed.

Data availability statement No data are available. All data relevant to the study are included in the article or uploaded as supplementary information. Data of survey are not publicly available aiming to preserve anonymity of information from participants.

Open access This is an open access article distributed in accordance with the Creative Commons Attribution Non Commercial (CC BY-NC 4.0) license, which permits others to distribute, remix, adapt, build upon this work non-commercially, and license their derivative works on different terms, provided the original work is properly cited, appropriate credit is given, any changes made indicated, and the use is non-commercial. See: http://creativecommons.org/licenses/by-nc/4.0/.

\section{ORCID iD}

Leandro Dragueta Delfino http://orcid.org/0000-0002-5359-8910

\section{REFERENCES}

1 Compernolle S, De Cocker K, Teixeira PJ, et al. The associations between domain-specific sedentary behaviours and dietary habits in European adults: a cross-sectional analysis of the spotlight survey. BMC Public Health 2016;16:1057-66.

2 Chastin SFM, Egerton T, Leask C, et al. Meta-Analysis of the relationship between breaks in sedentary behavior and cardiometabolic health. Obesity 2015;23:1800-10.

3 World Health Organization. Physical inactivity: a global public health problem. Geneva: World Health Organization, 2008.

$4 \mathrm{Nam}$ JY, Kim J, Cho KH, et al. Associations of sitting time and occupation with metabolic syndrome in South Korean adults: a cross-sectional study. BMC Public Health 2016;16:943-53.

5 Healy GN, Clark BK, Winkler EAH, et al. Measurement of adults' sedentary time in population-based studies. Am J Prev Med 2011;41:216-27.

6 Thorp AA, Healy GN, Winkler E, et al. Prolonged sedentary time and physical activity in workplace and non-work contexts: a cross-sectional study of office, customer service and call centre employees. Int J Behav Nutr Phys Act 2012;9:128.

7 Ryan CG, Dall PM, Granat MH, et al. Sitting patterns at work: objective measurement of adherence to current recommendations. Ergonomics 2011;54:531-8.

8 Hadgraft NT, Lynch BM, Clark BK, et al. Excessive sitting at work and at home: correlates of occupational sitting and TV viewing time in working adults. BMC Public Health 2015;15:899-912.

9 Maia EG, Gomes FMD, Alves MH, et al. Hábito de assistir televisão E sua relação com a alimentação: resultados do período de 2006 a 2014 em capitais brasileiras. Cad. Saúde Pública 2016;32:1-14.

10 Hsueh M-C, Rutherford R, Huang Y-H, et al. Are older adults without a healthy diet less physically active and more sedentary? Nutrients 2019;11:1119.

11 Araújo DSMSde, Araújo CGSde. Aptidão física, saúde E qualidade de vida relacionada saúde em adultos. Rev Bras Med Esporte 2000;6:194-203.

12 Vedovato TG, Monteiro I. Health conditions and factors related to the work ability of teachers. Ind Health 2014;52:121-8.

13 Cardoso JP, Ribeiro IdeQB, Araújo TMde, et al. Prevalência de DOR musculoesquelética em professores. Rev Bras Epidemiol 2009;12:604-14.
14 Dias DF, Loch MR, González AD, et al. Atividade física insuficiente no tempo livre $E$ fatores ocupacionais em professores de escolas públicas. Rev Saude Pub 2017;51:68.

15 Vaz M, Bharathi AV. How sedentary are people in 'sedentary' occupations? The physical activity of teachers in urban South India. Occup Med 2004;54:369-72.

16 Farahmand BY, Persson P-G, Michaëlsson K, et al. Physical activity and hip fracture: a population-based case-control study. Int $J$ Epidemiol 2000;29:308-14.

17 Saidj M, Menai M, Charreire H, et al. Descriptive study of sedentary behaviours in 35,444 French working adults: cross-sectional findings from the ACTI-Cités study. BMC Public Health 2015;15:379-89.

18 Owen N, Sparling PB, Healy GN, et al. Sedentary behavior: emerging evidence for a new health risk. Mayo Clinic Proceedings 2010;85:1138-41.

19 Brazilian Institute of geography and statistics. municipal human Developtment index, 2010. Available: https://cidades.ibge.gov.br/ brasil/sp/presidente-prudente/panorama [Accessed 14 Jun 2017].

20 Agranonik M, Hirakata VN. Cálculo de tamanho de amostra: proporções. Revista HCPA 2011;31:382-8.

21 Rosenberg DE, Norman GJ, Wagner N, et al. Reliability and validity of the sedentary behavior questionnaire (SBQ) for adults. J Phys Act Health 2010;7:697-705.

22 van der Ploeg HPet al. Sitting Time and All-Cause Mortality Risk in 222497 Australian Adults. Arch Intern Med 2012;172:494-500.

23 World Health Organization. Who technical report series. obesity: preventing and managing the global epidemic: report of a who consultation. Geneva, 2000.

24 Ministry of health. Surveillance system for risk and protective factors for chronic diseases by telephone survey. Brazil: Ministry of health, 2017. https://bvsms.saude.gov.br/bvs/publicacoes/vigitel_brasil_ 2017_vigilancia_fatores_riscos.pdf

25 Galduróz JCF, Noto AR, Nappo AS, et al. I Levantamento domiciliar nacional sobre O uso de drogas psicotrópicas: estudo envolvendo as 24 maiores cidades do estado de São Paulo. São Paulo: CEBRID/ Unifesp, 1999

26 Conner TS, Brookie KL, Carr AC, et al. Let them eat fruit! the effect of fruit and vegetable consumption on psychological wellbeing in young adults: a randomized controlled trial. PLoS One 2017;12:e0171206.10.1371/journal.pone.0171206

27 Baecke JA, Burema J, Frijters JE. A short questionnaire for the measurement of habitual physical activity in epidemiological studies. Am J Clin Nutr 1982;36:936-42.

28 Brazilian criteria for economic classification. Brazilian Institute of public opinion and statistics, 2015. Available: http://www.abep.org/ Servicos/Download.aspx?id=11 [Accessed 27 Dec 2019].

29 United Nations for Education Science and Culture OrganizationUNESCO. O Perfil DOS professores brasileiros: O que fazem, O que pensam, O que almejam - Pesquisa Nacional UNESCO. Moderna: Profile of Brazilian teachers: what they do, what they think, what they crave - National Survey] Sao Paulo, 2004.

30 Pearson N, Biddle SJH. Sedentary behavior and dietary intake in children, adolescents, and adults. Am J Prev Med 2011;41:178-88.

31 Chapman CD, Benedict C, Brooks SJ, et al. Lifestyle determinants of the drive to eat: a meta-analysis. Am J Clin Nutr 2012;96:492-7.

32 Healy GN, Dunstan DW, Salmon J, et al. Breaks in sedentary time: beneficial associations with metabolic risk. Diabetes Care 2008;31:661-6.

33 Pate RR, O'Neill JR, Lobelo F. The Evolving Definition of "Sedentary". Exerc Sport Sci Rev 2008;36:173-8.

34 van der Ploeg HP, Hillsdon M. Is sedentary behaviour just physical inactivity by another name? Int J Behav Nutr Phys Act 2017;14:142. 